\title{
Definición de caso sospechoso de gripe A(H1N1) 2009: razones para la discordancia
}

\author{
MJ. Purriños Hermida, P. Brañas Tato, A. Malvar Pintos, X. Hervada Vidal \\ Servicio de Epidemioloxía. Dirección Xeral de Saúde Pública e Planificación Sanitaria. \\ Consellería de Sanidade de Galicia. Santiago de Compostela. A Coruña. España.
}

En la Revista Pediatría de Atención Primaria se ha publicado un artículo en el que se concluye que las distintas comunidades autónomas españolas han utilizado definiciones diferentes para los casos sospechosos de gripe $\mathrm{A}(\mathrm{H} 1 \mathrm{~N} 1) \mathrm{v}$. La finalidad de la presente carta es matizar dicha afirmación e intentar explicar cómo, aun recogiendo diferentes datos, los sistemas de vigilancia pueden alcanzar su objetivo final.

La falta de concordancia que se recogen en las definiciones de gripe registradas en el citado artículo podrían deberse, efectivamente, a que cada comunidad autónoma se hubiese planteado una definición para caso sospechosos de gripe $\mathrm{A}(\mathrm{H} 1 \mathrm{~N} 1) v$ pero, dado que las definiciones se consensuaban entre todas las comunidades en el Subcomité de Vigilancia Nacional, parece más razonable pensar que se ajustasen a los criterios acordados entre ellas. Las variaciones observadas pueden explicarse por varias razones:

1. Hay dos aspectos relevantes que hacen lógica y necesaria la discrepancia encontrada en las definiciones: las distintas fechas en que estas se recogen y la fase diferente (contención o mitigación) en la que se encontraba cada comunidad. Así, lo excepcional de la situación planteada ante la declaración de fase VI de pandemia de gripe llevó a que la definición de caso en investigación (solo llamado caso posible en abril) tuviese, por ejemplo en Galicia, varias definiciones de caso diferentes entre el 27/04/09 (fecha en la que se pasó a fase IV) hasta finales de junio, ya que la distinta situación epidemiológica implicaba la necesidad de una definición distinta para cada momento². 
Por otro lado, la declaración de pandemia no implica una transmisión comunitaria sostenida (TCS) en todo un país a la vez, con lo que la fase de contención o mitigación en la que se encontraron las distintas comunidades autónomas no coincidieron exactamente en el tiempo.

2. Es importante destacar otro aspecto que se debe considerar: incluso en un mismo momento pueden estar en vigor dos definiciones diferentes para los casos en investigación. Definiciones con distinta sensibilidad en función del objetivo que se busque alcanzar con cada una de ellas. De este modo, en Galicia, mientras no hubo TCS conocida, la aplicación de la definición empleada para intentar detectarla y orientada a la toma de muestras era más sensible que la que se aplicaba para indicar el tratamiento con antivirales que, al incluir fiebre y criterios epidemiológicos, resultaba más específica.

\section{Bibliografía}

1. Hernández Merino A. Nueva gripe [A(H1N1) 2009]: definición de caso sospechoso. Revisión en la concordancia en los criterios de definición de caso utilizados en las distintas comunidades autónomas españolas. Rev Pediatr Aten Primaria. 2009;11:383-98.
En todo caso, los objetivos de los sistemas de vigilancia no establecen, como parece deducirse del citado artículo, la necesidad de un alto grado de precisión en el número de casos declarados, y para el cual serían necesarios otro tipo de trabajos, como las encuestas de seroprevalencia. En el caso de la gripe pandémica, los objetivos fueron: identificar las características clínicas y epidemiológicas de los casos, estimar el impacto que las formas graves pudiesen tener sobre los servicios sanitarios, conocer los posibles cambios que pudiesen aparecer en el virus, y contar con los datos necesarios para poder establecer la curva epidemiológica (estimando su intensidad e identificando el punto en el que nos encontramos en cada momento, sabiendo que, en cualquier caso, presenta siempre cierta área de incertidumbre), y todos estos objetivos establecidos se alcanzaron con éxito, independientemente de las posibles variaciones en la definición.

2. Vixilancia e resposta fronte ao virus da gripe $\mathrm{A}(\mathrm{H} 1 \mathrm{~N} 1) v$ mentres en Galicia non houbo transmisión comunitaria sostida. Bol Epidemiol Galicia. 2009;22 (2):1-5 [consultado el 06/08/ 2010]. Disponible en www.sergas.es/Mostrar Contidos_N3_T01.aspx?IdPaxina $=62613$ 